\title{
Creating Awareness on Vision and Mission Statements among Employee of Ebonyi State University-Nigeria: A Discourse
}

\author{
Emmanuel A., Ezekwe \\ Department of Public Administration, Ebonyi State University, Abakaliki-Nigeria \\ Dr. Sam, N. Egwu \\ Department of Public Administration, Ebonyi State University, Abakaliki-Nigeria
}

\begin{abstract}
The research was carried out to investigate the place of awareness on vision and mission statements among employee of Ebonyi State University-Nigeria; focusing on the implementation and challenges facing the objectives of the cherished statements. A theoretical analysis was adopted to achieve the purpose of the study. The result of the findings indicates that employees in Ebonyi State University are not accustomed with vision and mission statements. The study recommends that the University principal Officers should engage in a campaign on the primary role of these statements and how each employee's activity may help reposition the organization and achieve greater performance and motivate members concerned.
\end{abstract}

Keywords: Vision and Mission, non-awareness, performance, Motivation.

\subsection{INTRODUCTION}

Vision and mission statements have been considered by both practitioner and professional alike as a vital instrument for strategic management process especially public and private organizations (William, 2012). It is assumed that a good vision and mission statements drives strategy and reposition organization, motivate and infuse greater performance among employee. Similarly, significant number of universities in Nigeria have vision and mission statements which in order words maybe effective or dominant because the relevant stakeholders seems not to know or understand what the organization stands for both present and future. The situation as it may has created a gap and such need to be closed and create awareness among employee will go a long way to achieve the organizational goal, considering primary objective of the university like teaching, learning, research and community development.

Consequently, the implication reveals that in an attempt to prepare and communicate the vision and mission statements it was left on the hands of the top management team and such, the employee in the Ebonyi State University were seen not recognized. The highlighted practice in the system has placed the employees in the institution instead measuring up to the goals and expectation are seen experiencing increase and decrease performance; employee job dissatisfaction and turnover presently has been observed. Thus, developing vision and mission statements are collective responsibility of the relevant stakeholders to enable the internal and external determine direction of the institution and such align to achieve the objective and philosophy. Supporting the argument Mullane (2002) believes that vision and mission statements are useful for every day operations, it is not antiquated documents that exhibited and placed at the strategic position of an institution and also has the power to motivate employee when the future and present of the institution is known and effort geared towards sustaining the dream.

In related development articulated vision and mission statements are believed to motivate, shape behaviours, cultivate high levels of commitment and significantly affect positively on employee performance (Williams, 2012; Mullane, 2002). Studies like Mullane, (2002); William (2012) Noor, (2012) and Dermol, (2012) suggests that vision and mission statements have positive impact on profitability, motivate employee, shape behavior and cultivate high levels of commitment in an organization.

Consequently, it is assumed that vision and mission statements of institutions is an enduring statement of purpose that reveals product or service, markets, customers, culture and philosophy. However in practice most employee are not adequately informed on the importance of vision and mission statements of the organization thereby constituting problem to achieve the purpose and goal of having such needed document in the environment. Supporting the argument Klemm, Sanderson \&Luffman (1991)has it that such statements has the tendency of propelling organization's image external and to motivate employee. Ogbojafor, Olayemi\&Okonji, (2011) believed that in Nigeria the use of vision and mission statements not only as conventional slogans but it gives room for employees responsibilities and roles in attainment of business objectives. 
In an ideal situation vision and mission statements intend to project direction of management, employee, customers or clients, shareholders and communities where it operate (Williams, 2008). To a reasonable extent the configuration of vision and mission statement outside the employee has negative influence on the result of the organization proposes to achieve. It is when the employee understands the beginning then they may work to sustain the future of the organization. It is distinguishable according to strategic managers that vision and mission statements of public institutions are not the same thing and such needs to be separated (Sufi \& Lyons, 2002).

Presently some Universities adopted vision and mission statements for competitive advantage and distinguish one University from another by showing its uniqueness that differentiates it from others. Competitive advantage starts from strategic planning which has four components like vision, mission, strategy and action (Andrew, 2013). The most important aspect in strategic planning is formulating the vision and mission statements. Strategic planning successes depend largely on the proper identification and formulation of the vision and mission statements and add to the organizational identity (Ozden, 2011, Akeem, Edwin \&Fatai 2016). The intention is to create an external fidelity to the vision and mission of an organization, then to encourage a culture that describes and supports vision and mission statements (Durna\&Eren, 2002) cited in Akeem, et al, 2016. Researchers like Mullane, (2013), Simpson, (1994); Bart, Bontis\& Tagger, (2001) in Akeem, et al (2016) have mapped out how vision and mission statements can be used to establish a common and shared sense of purpose and also tool for channel through which the purpose of employees are formed and guided. Vision and mission statements guide all the activities of organization and business. Lynch (2000) believed that vision and mission statements are tools used in communicating organizations uniqueness in relations to ownership, resources or environmental circumstance. Mission and vision statements are believed to internally express desirable attitudes, work ethics value and culture that employees can operationalize in their choice of action and inaction and the study adopted social identity theory to elucidate information on the subject matter under discussion.

\subsection{Importance of Vision and Mission Statements in Organizational Strategy}

It is argued that vision and mission statements are of importance to the organization both private and public enterprise that understands the importance of competitive advantage.

1) Mission and Vision statements are standard and elements of the strategy of an organization.

2) Most known public Universities develop mission and vision statements, that serves as foundational guides in the establishment of organizational objectives.

3) The organization then develops strategic and tactical plans for achieving the objectives.

\subsection{Basic Components of Mission and Vision Statements}

It is assumed that components of mission statements most are been formulated guided by political, economic, socio-cultural, technological and environmental factors may be considered in the components of mission statements. In number of what supposed to be included researchers like Akeem et al, (2016) believed that an effective mission statement should include nine components: customers, products, or service, markets, technology, concern for survival, growth and profitability, philosophy, self-concept, concern for image, and concern for employees. The vision statement components according to David and David (2014) in Akeem et al, (2016) are stated below:

$\checkmark$ Survival, growth, and profitability's concern - is the firm dedicated to growth and financial security

$\checkmark$ Technology - is the organization current technologically

$\checkmark \quad$ Markets - where does the firm compete geographically

$\checkmark$ Philosophy - what are the key beliefs, values, objectives and ethical priorities of the institution

$\checkmark$ Concern for employees -does the firm value its human resources

$\checkmark$ Customers - who are the customers of the organization

$\checkmark \quad$ Self-concept - what is the firm's competence that distinguishes it from other firms 
$\checkmark$ Concern for public image - does the firm have concern for its community and external environment

According to Papulova, (2014) believed that vision as the strategic management creates the future through mental picture. It is always picture of excellence, something that the organization like Ebonyi State University's founding fathers bears in mind for the establishment of the University. Vision guides and ensures corporate existence of the organization because when the future seem to be certain all stakeholders intends to queue. Vision is an essential feature that can reposition institutions of higher learning. It provides the acceleration that can modify the institution when properly expresses confidence and hope about possibilities regarding the future direction achievement, Lipton (2003) in Papulova, (2014).

Interestingly, mission statements have the function of guiding all processes of strategic planning and explain what organizations want to be and whom they serve (Ozdem, 2011) in Akeem et al, (2016). Thus, the functions seem to be elastic based on the political, economic and environmental factors. Consequently, mission flows from vision, but in some cases; institutions were established based on the immediate opportunity. And it is believed that mission supposes to be precise to enable the concerned stakeholders recognize what it stands for and align to achieve institution's planning efforts. Researchers in this field of study like Papulova, (2014), Akeem et al, (2016) and Ogbojafor, Olayemi\&Okonji, (2011) argued that mission faces on the present and describes the client major processes and it informs the stakeholders about the out coming level of performance. To this end it is a statement of purpose of an institution both private and public and its target are on the both internal and external stakeholder. It motivates the employee and gives them direction in taking appropriate decisions and responsibilities that is in line with the objective and philosophy of the institution.

\section{$1.4 \quad$ Difference between Vision and MissionStatements}

\begin{tabular}{|c|c|c|}
\hline Item & Mission Statement & Vision Statement \\
\hline About & $\begin{array}{l}\text { It describes HOW to get to where you want to } \\
\text { be. Objective and major purpose of the } \\
\text { organization related to customer need and team } \\
\text { values are explained. }\end{array}$ & $\begin{array}{l}\text { It summarizes WHERE you want to } \\
\text { be. The values and purposes of } \\
\text { business are expressed. }\end{array}$ \\
\hline
\end{tabular}

\section{Answer \\ Time Function}

Change It responds to the question "what do we do? What makes us different?"

It talks about the present heading to the future. It outlines wide goals for the establishment of the organization. The principal function is internal; that explains the salient organization's success measure or measures and its principal audience is the leadership, team and stockholders

It can change, but it must still be tied to the core values customer needs and vision of the firm

\section{Developing a statement}

\section{Features of an effective statement}

What are we doing today? For whom? Of what benefit? That is to say, why we do what we do? What, for Whom and Why?

Reason and ethics of the organization: who are the primary "client" (stakeholders) of the organization? What are the duties of the organization towards them?
It responds to the question, "where do we aim to be?"

It talks about the future

It outlines where organization will see itself some years from now. It motivates the firm to put is its best. It gives an understanding of the reason for the existence of the organization

As the organization evolves, it might be tempted to change the vision. However, the statements describe the foundation of the organization, therefore, there should be a reduction in change to the minimum. Where are we going? When are we getting to the stage? How are we going to do it?

Should be clear, concise and unambiguous: describing a happy future (Hope); remarkable and interesting expression; accurate aspirations, possible adjustment with values and culture of the organization 


\subsection{Development of Vision Statement}

Vision is a critical mental roadmap to the success of any public institution. It is a catalyst that drives an organization through the route of its growth. The vision drives an organization future existence for the survival and sustainability to appreciate long term benefits of existence in a community. According to Papulova (2014) there are various ways of developing vision statement:

$>$ Intuition: This is a natural way of discovering and developing vision. It is attributed that visionaries are also founders of organizations who has the potential to lead the whole organization towards vision achievement.

A Team Approach: another way to develop vision statements are working collectively with people that can bring unusual ideas, views and inspirations can be very beneficial and result in creative and innovative solutions. Every individual has abilities and an incredibly large capacity of mind. If we consider that there is team of people who are creative and are thinking strategically, we could apply the saying, it is believed that "two good heads are better than one".

The rational approach to vision development is another possible way. This approach adopted rational and logical thinking. In this case we rely on analysis and synthesis, induction and deduction, comparison and other techniques of empirical investigation. But this approach will never lead us to new revolutionary or radical vision because it relies on suggested techniques and practices based on analyzing information from the past. Rational thinking is a conservative approach that will never lead us to creative solutions. The possibility is to adapt the vision of another organization. We can be motivated by the vision of another organization and understand its importance and significance.

According to Papulova (2014) further deduced that vision may or may not find its expression in vision statements. The length and complexity of the vision statement differ between organizations. Consequently, Henery, (2008) suggested that the vision statement be:

- $\quad$ Easy to understand

- $\quad$ Easy to remember

- Positive

- Motivational

- $\quad$ Inspiring

- Attractive

- Challenging

- $\quad$ Future-oriented

The public institution like Ebonyi state University and its employees should be identified with the vision statements. It is assumed that a good vision needs not only visionaries but most needed good leaders who can communicate the vision to both internal and external stakeholders.

\subsection{Place of Vision and Mission Statements among Employees.}

Interestingly, Noordin \& Jusoff (2009) assumed that having a competent vision and mission statement may lead to a world class university, the university needs to have world class academic employees that are dedicated, competent, knowledgeable, and above all committed to the university and their career. But all these attributes may likely diminish if the employee or the members of the employee perceived that they are not experiencing motivation in the institution to results may be in doubt (Ezekwe \& Onwe, 2014). It is empirically supported by researchers like (Mullane, 2002; Collins \&Poras, 1991; Daniel, 1992, Klemm et al, 1991) in Darbi (2012). Thus it tends to motivate, shape behavior, cultivate high level of commitment and ultimately impact positively on employee performance. Ebonyi State University vision and mission statement is capable of 
motivating and increase performance among employee, because of its quantification and measurement of their actions. The employee that desired to be rated best in the special area of discipline needs to be familiar with vision and mission statement of the University and thus, configure the employee for greater performance in the areas of specialty (Ezekwe \& Onwe, 2014).

The complete tasks of unveiling vision and mission statements are anchored on constant awareness/campaign and employee motivation is highly needed. This could lead to increase in performance. This applies not only to the interaction between superiors and colleagues, but also to the way in which we treat all those who approach us with concerns and requests (Ezekwe \& Onwe, 2014). Thus, as part an institution where people from many different nations and cultures come together to work, learn, teach, and do research management may be committed to promote the integration of different nationalities in the system based on the culture, values/beliefs cherished for strategic management process.

The Ebonyi State University, principal officers can use vision and mission statements to configure the employees by creating awareness as the medium to align the task of challenging responsibilities and are willing to make decision. The quality of employees and colleagues cannot merge unless adequate awareness and stakeholder's campaign help and support them in achieving the goals and objectives, (Ezekwe \& Onwe, 2014). The employee's performance align to represent the interest and demands of the institution's responsibility and taking into account the strategic goals and tasks of the system as a whole. The employees expected to be motivated and secure a greater performance, awareness and motivation, to a reasonable extent in order to maintain attractive workplaces, which anchored on commitment and efficient community development. In addition, goal-oriented information transfer, bureaucratic decision-making processes, and complex procedures are crippled because the important requirements for the adequate service delivery is in the mind of the employee that is the mission statement is driving force. The vision and mission statement is capable of supporting, motivate and boost morale of the employee's performance in the institution collectively.

Managing employee's motivation and greater performance is really about configuring employee time, talent and energy to support institution's strategy. Though some time already clarified the institution's strategic goals, defines the employee roles accordingly, and recruited personnel that can best perform in those roles assigned task for the right direction to be accomplished. It is assumed that the daily tasks, motivation, commitment and professional development and competence are derived by the vision and mission statement. The strategic goal is consistently to improve research, administrative clouds and to adapt them to the desires and expectations of the stakeholders.

The University's culture helps to shape the action of the employee. This is because the employees came from various nationalities to perform their tasks in the institution, it is not surprise that when the culture is not amicable, and many may look for a better place. These are seen in most cases when the management insists to train the staff, or sponsor them on conference and related programme that would boost their performance in various areas of discipline. The culture anchored on creative research/output, academic award in terms of grants, and rich website in terms of web ranking. The employee as the members of the social system needs to know that they can depend on the culture of institutions, protect and nurture them as they struggle with career and life issues (Ezekwe \& Onwe, 2014). In line with highlighted, the vision and mission statement speaks volumes on performance and high level of commitment to the things they think are important. When the employees are appreciated they are motivated.

It is assumed that vision and mission statement can configure the employee role and motivate them in the institution. It is reorganized in some institution in the country that when an employee performed his/her tasks very well awards await such person. The motivation could be double promotion, cash and commendation letters to boast the morale of employee for greater performance. Similarly, the institution principal officers may take a look on factors that drive the members of staff to perform well in their various areas of discipline what is the employee beahviours that can support the institution's vision and strategic goals, what leadership actions that can configure members of the employee and gear motivation that may support the institution strategic goals. Therefore, if these questions are appropriately attended to and handled as expected, it is assumed that institution's strategic goals and decision-making process over time will encourage performance effectively. Therefore, motivation could arise as a reward because most effective institutions tie their rewards to performance in various ways, depending on the political, economic and environmental configuration.

Both practitioner and professional alike assumed that Ebonyi State University vision and mission statements significantly intend to influence employee performance and such properly crafted needs awareness/campaign, employee motivation and commitment. On the contrary, significant percentage of the employee in the system is not adequately aware of their institution's vision and mission statements. Thus, evidently has affected their performance in their various areas of discipline and responsibilities. Therefore, the essence of this research is to reposition the Nigerian Universities employees and using Ebonyi State University as a reference point for greater performance and to align among other competitive citadel of learning around the globe. 


\section{$2.1 \quad$ Specimens of Vision and Mission Statement in Nigeria.}

\subsubsection{Ebonyi State University, Abakaliki}

$\checkmark$ Vision: To rank among the best citadels of learning in the world with excellence in learning, research and community services

$\checkmark$ Mission: To provide a conducive atmosphere for teaching, learning, research and rapid development in order to transform the hitherto, untapped, abundant unskilled, human resources in Ebonyi State University into skilled manpower.

\subsubsection{Covenant University}

$\checkmark$ Vision: To be a leading world-class University, committed to raising a new generation of leaders in all fields of human endeavours

$\checkmark$ Mission: To create knowledge and restore the dignity of the black man via a human development and total Man Concept driven curriculum employing innovative, leading edge, teaching and learning methods, research and professional services that promote integrated, life-applicable, life-transforming education relevant to the context of science, technology and human capacity building.

\subsection{Discussions on the specimen of the University's vision and mission statements}

On the contrary evidently from the specimen of vision and mission statement of the sampled organization Convent University mission seem to be difficult to memorize by both internal and external stakeholders. While Ebonyi State University is better prepared mission statements and such its employee are better place and can derive organizational strategy motivated. It is proposed that for any organization to survival on its strategic plan, there must be articulate formulation of vision and mission statements and gives room for collective responsibility in achieving the organizational objective. Interestingly, for any strategic plan to excel is a dependent of articulate formulation of vision and mission statements and collective participation (Ozdem, 2011). Thus, the litany of vision and mission of any institution must be precise to enable the stakeholder adapt and make maximum use of such crafted for the survival and healthy competition in the community.

Communication of an effective vision and mission statements can possible help institution of higher learning in gaining and preserving competitive advantage (Desmidt, Prinzi \& Decrammer, 2011). It is a revelation that University that have articulate vision and mission statement well disseminated, understand and collectively shared have been observed to perform better than organization without such cherished document. The litany of vision and mission statements in both public and private institutions derives majorly on the premise of the fact that it gives purpose and direction to the organization and legitimates its existence. Significant number of the Universities in Nigeria adopted vision and mission statements to direct their activities, relate their organization within and outside the world in order to sustain the competitive advantage. The development of vision and mission statements can significantly impact on the survival and growth of a business (Analoui \& Karami, 2002), in Ganu (2013). What is obtainable elsewhere, may also take place in Nigerian environment that such crafted document be unveiled within the organization's offices, and ensure that every member of the organization work towards goal realization. To a reasonable extent it communicates direction, direct decision making among the management and to motivate employees. Often these litanies of vision and mission statements are given to employees without a full understanding of their influences on the individual and most time keep the employee unaware and most time seen during annual presentation.

\section{Conclusion}

Given that vision and mission statements are vital tool for strategic management in an organization and have the propensity to motivate, induce greater performance and communicate present and future direction of the institutions. Managers are advised to plan and use it more effectively. It is appealing that all employees should be adequately educated or create awareness on the primary role of these statements and how each member's activity may help reposition the organization and achieve greater performance and motivated members concerned.

\section{REFERENCES}

Agwu, E.M. (2015). Lecture note on Advanced Strategic Management, Covenant University, Ota, Ogun state. Unpublished, June 26th, 2015. 
Akeem, A. T., Edwin, A. M. \&Fatai, A. L., (2016) Vision and Mission in

Organization: Myth orHeuristic Device? The International Journal of Business \& Management, vol. 4 (3) 127- 134

Analui, F. and Karami, A. (2002)."CEOs and the development of the meaningful Corporate Governance, Vol. 2 (3) 13-20.

mission statement",

Bart, C. K., Bontis, N., \& Tagger, S., (2001) A model of the impact of mission performance. Management Decision. Vol. 39 (1) 9-18

statements on firm

Collins, J. C. \&Poras, J. I. (1991) Organizational vision visionary organizations California Review, Fall.

Management

Daniel, A. L., (1992) Strategic Planning-the role of the Chief Executive, Long Range Planning, vol. 25.

Darbi, W. P. K., (2012) of mission and vision statements and their potential impact on employee behavior and attitude: the case of a public but profit-oriented tertiary institutions. International Journal of Business and Social Science, vol. 3 (14

David, M. A., David, F. A., \& David, F. A. (2014) Mission Statement Theory and Practice: A Content Analysis and New Direction. International Journal of Business, Marketing, \& Decision Sciences.Vol. 7, 1.

Deermol, V., (2012) Relationship between mission statement and company performance. Management Knowledge and Learning International Conference, 891-899.

Desmidt, S., Prinzie, A., \&Decramer, A., (2011) Looking for the value of mission statements: A meta-analysis of 20 years of research. Management Decision, 49, 468-483.

Durna, U. \&Eren, V. (2002).Kamusektorundestratejikyonetim. AmmeIdaresi Dergisi, 35 (1), $55-75$.

Ezekwe, E. A., Onwe, S. O. (2014) configuration of Nigerian tertiary institutions employee using mission statements: A discourse. International Journal of Political Science and Administration, vol. 2 (3) 23-32.

Ganu, J ((2013) Institutional Mission Statements and Attitudinal Outcomes of Selected.

Kle, M., (1996) Mission Statements: Selling corporate values to employees, Long Range Planning, Vol. 24 (3) 73-78.

Klemm, M., Sanderson, S., \& Luffman, G. (1991). Mission statements: Selling corporate values to employees. Long Range Planning, 24(3), 73-78.

Lynch, R. (2000). Corporate Strategy. Pearson Education, Harlow.

Mullane, J. V., (2002) The Mission Statement is Strategic Tool: when used properly. Management Decision, vol 6, 257-272.

Noor, A. A., (2012) Mission Statement and Company Performance: Evidence from Malaysia. International Journal of Business and Behavioural Sciences, vol. 2 (4) 98-106.

Noordin F. \& Jusoff K., (2009) Levels of job satisfaction amongst Malaysian academic staff. Asian Social Science Journal Vol. 5 (5).

Oghojafor, B. E. A., Olayemi, O. O. \& Okonji, P. S. (2011).Enhancing organization's performance through effective vision and mission. Chinese Business Review, 10: 1071- 1075. 
Ozdem, G. (2011). An analysis of the mission and vision statements on the strategic plans education institutions. Kuramve Uygulamada Egitim Bilimleri, Educational Sciences: Theory \& Practice.

Papulova, Z., (2014) The Significance of Vision and Mission Development for Enterprises in Slovak Republic. Journal of Economics, Business and Management, vol. 2 (1) 12-16.

Simpson, D. (1994). "Rethinking mission and vision”, Planning Review, Vol. 22,

911.

Stryker, S., \&Serpe, R. T. (1982) Commitment, identity salience, and role behavior: a theory and research example.In W. Ickes \& E. S. Knowles (Eds.), Personality, roles, and social ～behavior pp199-218.

Stryker, S., \&Serpe, R. T. (1994) Identity salience and psychological centrality: equivalent, overlapping, or complementary concepts? Social psychology quarterly, 57, 16-35.

Sufi, T., \& Lyons, H. (2002). Mission statements exposed. International Journal of Contemporary Hospitality Management, 15(5), 255-262.

William, P. K. D., (2012) Of Mission and Vision Statements and their Potential Impact on Employee Behaviour and Attitudes: The Case of A Public But Profit-Oriented Tertiary Institution. International Journal of Business and Social Science, Vol. 3 (14) 95-109. 